\section{Detection of irradiated food}

SIR-In searching for a reliable detection method to identify irradiated food ${ }^{1}$, Moriarty et al. suggested a test based on the thermoluminescence (TL), emitted on heating irradiated spices from ambient temperature to below combustion ${ }^{2}$. The authors, however, admitted that the errors in their study were still too large to be satisfactory, and other doubts have since arisen ${ }^{3}$. We now report that it is the inorganic dust in spices that is mostly responsible for $\mathrm{TL}$ and that an improved test can be based on the separated dust.

Fine-grained dust was separated from various spices (cumin, green pepper, sage, rosemary, lovage, oregano, dill weed and savory) by centrifugation following wetsieving in an ultrasonic bath of analytical grade acetone. About $1.5 \mathrm{mg}$ of dust

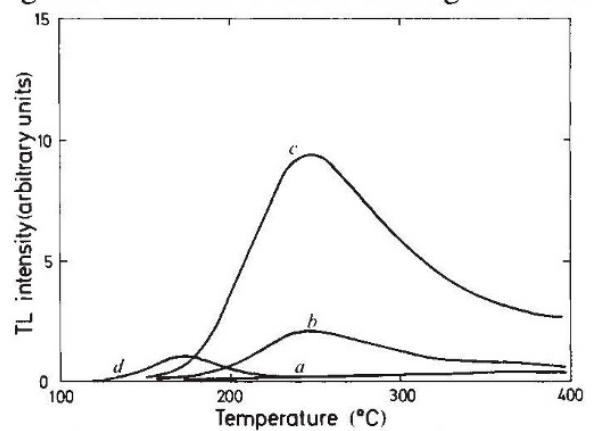

TL glow curves of dust samples collected from irradiated sage. Measurements six days after irradiation at room temperature and subsequent storage at $60^{\circ} \mathrm{C}$ in a desiccator. $a$, unirradiated; $b, 1 \mathrm{kGy} c, 10 \mathrm{kGy}$; , ultraviolet exposure.

particles is obtained from $3 \mathrm{~g}$ of spice. The dust particles were deposited as a $5 \mu \mathrm{m}$ thick layer on aluminium disks $(5 \mathrm{~mm}$ in diameter, $0.5 \mathrm{~mm}$ thick) by evaporating the acetone in a desiccator. After exposing whole spices or separated dust samples to absorbed doses of 1,10 and 20 kilogreys $(\mathrm{kGy})$ at a ${ }^{(*)} \mathrm{Co} \gamma$-ray source (Gammacell 220, AECL, Canada) at a dose rate of about 3 kGy h ', TL analysis (Harshaw 2000) of the dust samples was performed with a linear heating rate of $8^{\circ} \mathrm{C} \mathrm{s}{ }^{1}$, an upper read-out temperature of $400^{\circ} \mathrm{C}$, and with dry nitrogen gas flushing the measuring cell. The aluminium disks fit the dimensions of the heater planchet.

Dust samples were found to emit a significant TL signal only if prepared from irradiated, rather than unirradiated, spices. TL measurements up to $400{ }^{\circ} \mathrm{C}$ or more did not cause detectable changes in either the appearance or radiation response of samples, suggesting that the separated dust is inorganic.

The thin layer of the dust samples allowed the structure of the TL glow curves to be resolved. Most had a single maximum between 225 and $250^{\circ} \mathrm{C}$ (see figure). Up to about $10 \mathrm{kGy}$, but not above, a distinct increase in TL output was found. Repeated irradiation and evaluafollowed by centrifugation. tion of the dust samples showed that the TL response is highly reproducible, with coefficients of variation $\leqslant 5$ per cent ( 90 per cent confidence level). On the basis of isothermal decay experiments at 60,100 and $150^{\circ} \mathrm{C}$, the half-life of the TL signals was determined to about 5 years at room temperature.

Ultraviolet light was also found to give rise to TL but with a different glow peak temperature of about $175^{\circ} \mathrm{C}$ (see figure). This TL may account for the report ${ }^{3}$ that some non-irradiated samples are identified as irradiated by TL.

In conclusion, TL measurements on

SIR-Thermoluminescence (TL) is one of several phenomena being investigated to develop reliable methods for identifying irradiated foods. Repeated reports ${ }^{1-3}$ have claimed that herbs and spices themselves exhibit TL; and this has been proposed as the basis for official testing in West Germany. Our own feasibility work from 1986 onwards demonstrated the strength and reproducibility of TL signals from soil adhering to potatoes irradiated at a typical dose for inhibiting sprouting ( 0.1 kilogrey). We soon came to the view that these results, taken together with observations of positive signals from freshly irradiated herb and spice samples, could be adequately explained by the presence of mineral grains adhering to sample surfaces ${ }^{6}$. This has been confirmed by our experimental work over the past two years, full details of which are in press ${ }^{7 . *}$. Our purpose here is to summarize the evidence for this view and to show that it has important practical consequences for identifying irradiated foodstuffs.

The TL responses of more than 200 samples of herbs, spices, seasonings and vegetables have been examined before and after gamma irradiation with our 200-TBq "Co facility. TL glow curves recorded at $6{ }^{\circ} \mathrm{C} \mathrm{s}{ }^{1}$ from ambient temperatures to $500{ }^{\circ} \mathrm{C}$ show a remarkable consistency of inorganic dust separated from spice samples should allow reliable identification of irradiated spices. The method can probably be extended to other food that contains dust.

\section{H. Y. GÖKSU-ÖGELMAN D. F. REGULLA}

Gesellschaft für Strahlen- und

Umweltforschung,

\section{München,}

D8042 Neuherberg, FRG

1. Bögl, K.W., Regulla, D.F. \& Suess, M.J. (eds) Health impact, Identification and Dosimetry of Irradiated Foods ISH-Heft 125 (WHO/BGAVGS, Neuherberg, 1988).

2. Moriarty, T.F., Oduko, J.M. \& Spyrou, N.M. Nature 332, 22 (1988).

3. Heide, L. \& Bögl, K.W. Int. J. food Sci. Tech. 22, 93-103 (1987).

form. With the exception of seasoning mixtures containing salt (which produces its own glow shape) all samples show similar characteristics to those associated with feldspar and polymineral loess samples in TL dating. Dating studies using similar equipment ${ }^{9}$ have shown that these minerals have high-temperature TL sensitivities, ranging from $10^{3}$ to $10^{6}$ photons $\mathrm{s}^{-1} \mathrm{mg}^{-}$ $\mathrm{Gy}^{-1}$. Even allowing for saturation effects in the $1-10-\mathrm{kGy}$ dose region, microgram quantities of such materials could easily account for all the signals observed from herbs and spices.

Many samples can be correctly identified as irradiated or unirradiated on the basis of signal strength alone. More than 90 per cent of irradiated samples can be identified using thresholds just greater than 1,000 counts $\mathrm{s}^{-1} \mathrm{mg}^{-1}$. Nevertheless, this approach is hampered by high variance for irradiated samples and blanks and also by a significant number of lowsensitivity samples showing false negative results.

When the extraneous mineral grains on sample surfaces were separated from the organic bulk and the TL of the two phases was separately measured, TL sensitivity enhancements of $10^{3}$ or more and improved signal-to-blank ratios were seen in mineral phases (Fig. 1). These experiments clearly show that the TL is associated with the
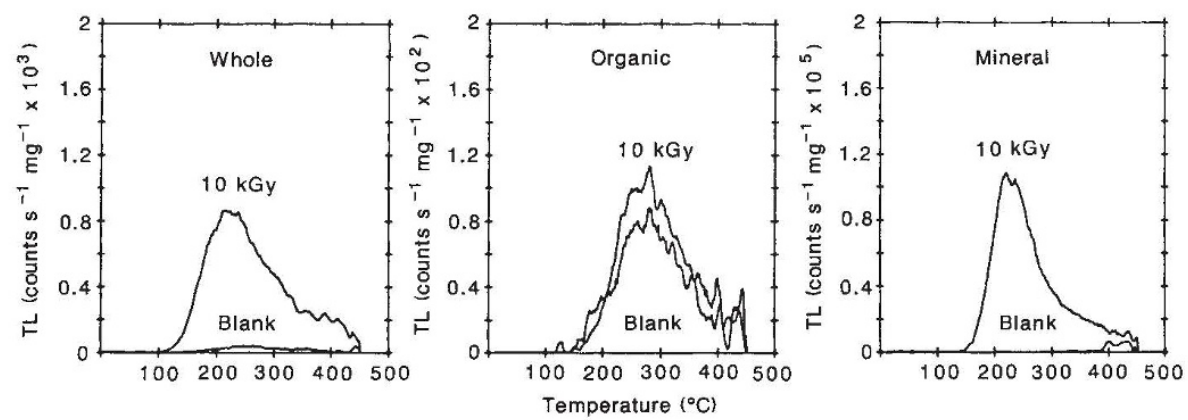

FIG. 1 Comparison of TL glow curves recorded from irradiated (10 kGy) and unirradiated (Blank) portions of whole sage and its organic or inorganic fractions. TL strength expressed as weightnormalized photon count rates obtained from an SURRC research reader incorporating an EMI $9883 Q B$ photomultiplier filtered with $K G 1$ and $7 / 59$ glass filters. Samples mounted on stainless steel disks $\left(0.25-\mathrm{mm}\right.$ thick, $1-\mathrm{cm}$ diameter) and heated in $\mathrm{O}_{2}$-free $\mathrm{N}_{2}$ at $6{ }^{\circ} \mathrm{C} \mathrm{s}^{-1}$. Minerals separated by ultrasonic agitation in solutions of sodium polytungstate (density $1.6 \mathrm{~g} \mathrm{~cm}^{-3}$ ) 